\title{
EFEITO DE MISTURAS DE BENTAZON E PARAQUAT NAS PLANTAS DANINHAS E NA CULTURA DO FEIJAO (Phaseolus vulgaris L.)*
}

R. Victoria Filhow:s

RESUMO

A presente pesquisa foi conduzida na Escola Superior de Agricultura "Luiz de Queiroz", em Piracicaba, SP, no ano de 1981, com o objetivo de se es tudar o comportamento dos herbicidas bentazon e paraquat, aplicados isola damente ou em misturas, em alguns cultivares de feijão e algumas espécies de plantas daninhas. Para tanto, foram instalados dois experimentos a campo, sendo um "das secas" e outro "das äguas" de 1981. Os culti vares de feijão estudados foram $\mathrm{Ca}=$ rioca e Moruna. Os tratamentos uti-

$*$ Entregue para publicação em 29/12/83.

Parte da dissertaçáo apresentada pelo primeiro autor à E.S.A. "Luiz de Queiroz", USP, Piracicaba, SP.

$\therefore$ Fundação IAPAR, Londrina, PR.

$\therefore \therefore$ Departamento de Agricultura e Horticultura da E.S.A. "Luiz de Queiroz", USP, Piracicaba, SP. 
1 izados foram os seguintes: bentazon a 0,48 e $0,96 \mathrm{~kg} / \mathrm{ha}$; paraquat a 0,05 e $0,10 \mathrm{~kg} / \mathrm{ha}$ e as misturas de tanque com $0,48+0,05 ; 0,96+0,10 ; 0,48+$ $+0,10$ e $0,96+0,05 \mathrm{~kg} / \mathrm{ha}$ de bentazon + paraquat, respectivamente. Foram realizadas avaliaçōes visuais da porcentagem de injüria nos cultivares de feijão e nas espécies de plan tas daninhas, sendo utilizada a förmula de Colby para verificação dos efeitos das misturas. Os resultados mostraram que as misturas exerceram evidente efeito antagonístico nos cultivares ensaiados. Os tratamentos não influíram na produção dos cultivares Carioca e Moruna. Em solos arenosos e com baixa precipitação, o sinergismo das misturas ficou evidenciado na guanxuma (Sida glazio viik. Sch.) e na beldroega (PortuZacca oleracea L.). Em solos argilo sos, com precipitação normal, os efeitos sinergísticos foram evidentes no capim-marmelada (Brachiaria plantaginea (Link.) Hitch.), capim-pé-de-galinha (fileusine indica (L.) Gaertn.) e no apaga-fogo (Alternanthera ficoidea (L.) R. Br.).

\section{INTRODUÇÃO}

o feijão (Phaserilus vulgaris L.) ë um dos principais produtos agrícolas do Brasil, constituindo-se numa das principais fontes de proteínas para a nossa população. O uso de herbicidas na cultura do feijão é prática bastante difundida nos países desenvolvidos. No Brasil, 
entretanto, apenas agora essa prätica começa a tomar impulso, principalmente pelos agricultores que cultivam es sa leguminosa em grande escala, utilizando uma tecnolo= gia de produção mals avançada.

GOWING (1960), estudando a interação entre bórax e arsênico propôs o seguinte: se $x$ é a porcentagem de redu cão no crescimento provocada pelo agente mais tóxico e $\bar{y}$ a porcentagem de redução no crescimento provocada pelo agente menos tóxico, então $x+(100-x) y$ seria a toxici dade esperada da mistura.

A partir dessa idéia, COLBY (1967) propôs a seguin te equação:

$$
E=\frac{x+y(100-x)}{100}
$$

onde:

$x=$ porcentagem de inibição do crescimento pelo herbicida "A" a " $\mathrm{p}$ " Ib/A;

$y=$ porcentagem de inibiçäo do crescimento pelo herbicida "B" a "q" Ib/A;

$E=$ porcentagem "esperada" de inibição do crescimento pe los herbicidas "A + B" a " $p+q$ " Ib/A.

Quando a resposta observada for maior que a espera da, o efeito serä sinergístico; quando for menor que $\bar{a}$ esperada, serä antagonístico e quando forem iguais o efe $i$ io será aditivo.

Inümeros trabalhos de pesquisa são citados na lite ratura, onde os autores utilizam o método de Colby parā quantificar os efeitos das misturas de herbicidas, como PRENDEVILLE et alii (1969), estudando as misturas de EPTC com 2,4-D, EPTC com $2,4,5 T$ e de EPTC com dicamba. Outros autores também utilizaram esse método como HAMILL. et ali i (1972), AKOBUNDU et alii (1975), SCHWEIZER (1979) e HATZIOS (1981). 
- paraquat tem sido largamente pesquisado em mistu ra com outros herbicidas, notadamente com os residuais, visando ao controle de plantas daninhas no sistema de plantio direto (TRIPLETT \& LYTLE, 1972; HICKS et alii, 1976; PAROCHETTI, 1979; SIMONDS \& BANKS, 1981). Alëm de ser estudado em mistura com outros herbicidas nos sistema de plantio direto, o paraquat foi também testado em mistura com outros herbicidas em culturas jä estabelecidas, quer anuais ou perenes. MORAES et alij (1966) em São Paulo, verificaram que a mistura de paraquat + fluometuron proporcionou um controle superior àquele feito por cada um dos produtos aplicados isoladamente, em cultura de café de 15 anos de idade. FRANCO $\varepsilon$ CATTANEO (1974) no Paraná, também em cultura de café, verificaram que a mistura de paraquat + ametryne deu um controle superior ao do paraquat aplicado isoladamente.

0 bentazon foi tambēm estudado em mistura com diversos herbicidas. RAMOS (1976) no Paranā, verificou que o bentazon reduziu o efeito do diclofop no controle do capim-marmelada, quando misturados. KAPUSTA et alii (1978), em lllinois, entretanto, verificaram que a mistu ra de tanque de bentazon + acifluorfen foi mais eficiente do que cada produto apl icado isoladamente, no controle de Ipomoea hederacea (L.) Jacq. na cultura de soja. PAULO et alii (1980), em São Paulo, observaram efeitos sinergísticos no controle de diversas espécies de plantas daninhas com a mistura de bentazon + mefluidide. RET ZINGER JR. et alii (1981) na Louisiana, EUA, verificaram qua a adição do acifluorfen reduziu o antagonismo existente entre o BAS-9052 e o bentazon.

A mistura paraquat + bentazon foi estudada em 0regon, EUA, pela OREGON STATE UNIVERSITY (1979) em cultura de menta. Os resultados mostraram que a adição do bentá zon reduziu significativamente a injüria visível na menta, caracterizada por necrose e atrofia, observada nos tratamentos com paraquat aplicado isoladamente.

0 objetivo da presente pesquisa foi estudar o comportamento do bentazon e do paraquat aplicados ent área 
total, isoladamente ou em misturas, em diferentes doses, sobre alguns cultivares de feijão e sobre algumas espécies de plantas daninhas, utilizando-se, para tanto, de produtos comerciais.

MATERIAL E METODOS

Os experimentos foram conduzidos em condições de campo, nas safras "das águas" e "das secas" de 1981, jun to ao Departamento de Agricul tura e Horticultura da ESAL $\bar{Q}$ em Piracicaba, SP, Brasil. O delineamento experimental adotado foi o de blocos ao acaso com parcelas sub-dividi das, com 10 tratamentos e 4 repetições, correspondendo as parcelas aos tratamentos herbicidas e as sub-parcelas aos cultivares. Os cultivares utilizados foram Carioca e Moruna. O espaçamento foi de $0,50 \mathrm{~m}$ entre linhas e a ärea úti $i$ de cada sub-parcela foi de $2,0 \times 4,0 \mathrm{~m}$.

0 experimento "das secas" foi semeado dia 20/02/81 em solo com $79 \%$ de areia, $9 \%$ de limo, $12 \%$ de argila e $0,72 \%$ de matéria orgànica, ocorrendo $16,6 \mathrm{~mm}$ de chuva nos primeiros 10 dias e $60,8 \mathrm{~mm}$ de chuva nos primeiros 30 dias após a semeadura. 0 experimento "das àguas" foi semeado dia $15 / 11 / 81$ en solo com $31 \%$ de areia, $28 \%$ de 1 i mo, $41 \%$ de argila e $3,38 \%$ de matéria orgânica, ocorrendo $76,3 \mathrm{~mm}$ de chuva nos primeiros 10 dias e $285,0 \mathrm{~mm}$ de chu va nos primeiros 30 dias após a semeadura.

A aplicação dos tratamentos foi feita 18 dias após a emergência do feijão, com pulverizador costal à pressão constante $\left(\mathrm{CO}_{2}\right)$ com barra de $2 \mathrm{~m}$ de comprimento, com 4 bicos $80.03 \mathrm{em}$ leque, distanciados $50 \mathrm{~cm}$ um do outro, pressão de $2,1 \mathrm{~kg} / \mathrm{cm}^{2}$, gastando se $300 \mathrm{litros} / \mathrm{ha}$ de calda.

Os tratamentos, além das testemunhas capinada e sem capina foram: bentazon a 0,48 e $0,96 \mathrm{~kg} / \mathrm{ha}$; paraquat 
a 0,05 e $0,10 \mathrm{~kg} / \mathrm{ha}$; e as misturas de tanque a $0,48+$ $+0,05 ; 0,96+0,10 ; 0,48+0,10$ e $0,96+0,05 \mathrm{~kg} / \mathrm{ha} \mathrm{de}$ bentazon + paraquat, respectivamente.

o critērio de avaliação adotado foi o da "porcenta gem de injüria"l através da avaliaçäo visual, realizadā aos 2, 4, 6 e 8 dias após a aplicação, após o que os ensaios foram totalmente capinados e mantidos no limpo até a colheita, com exceção da testemunha sem capina. A ve rificação dos efeitos sinergísticos e/ou antagonísticos foi feita pela förmula de Colby, onde: $x=$ porcentagem de injüria observada, provocada pelo bentazon à dose db; $y=$ porcentagem de injúria observada provocada pelo para quat à dose dp e $E$ = porcentagem de injüria esperada, pé la mistura de bentazon + paraquat, às doses $d b+d p$, res pectivamente. Se a injüria observada na planta foi maiōr que a esperada, o efeito da mistura foi sinergístico, in dicado com sinal $(+)$; se foi menor que a esperada, o efe $\vec{i}$ to foi antagonístico, indicado com sinal (-) e se foram iguais, o efeito foi aditivo, indicado por (0). Nos qua dros que mostram esses efeitos, os valores da injüria es perada (E) estão entre parênteses.

As espëcies de plantas daninhas presentes no experimento "das secas" foram: capim-colchão (Iigitiaria sanguinalis (L.) Scop.), guanxuma (sida glaziovii. K. Sch.) e beldroega (Portulacca oleracea L.), sendo a primeira espécie a dominante. No experimento "das äguas", as espécies de plantas daninhas presentes foram: capim-marme lada (Brachiaria plantaginea (Link.) Hitch.), capim-pe-de-galinha (Eleusine indica (L.) Gaertn.), carrapicho-de-carneiro (Acanthospermum hispidion D.C.) e apaga-fogo (Alternanthera ficoidea (L.) R. Br.), sendo esta ültima, a espécie dominante. 


\section{RESULTADOS E DISCUSSAO}

Nas condiçōes em que os experimentos foram realiza dos, ficou bastante evidente, pelas avaliaçöes visuais, - efeito antagonistico das misturas sobre os cultivares de feijäo ensaiados. Os efeitos fitotöxicos do paraquat aplicado isoladamente, de uma forma geral, permitiram re cuperação da cultura com o passar do tempo. Como o bentazon é praticamente seletivo aos cultivares, os efeitos antagonísticos das misturas também foram sendo reduzidos à medida que o tempo passava (Tabelas 1, 2, 3 e 4).

A adição do bentazon reduziu a injüria visível pro vocada no feijoeiro pelo paraquat, atuando como um "ageñ te protetor" dessa cultura, contra os efeitos fitotóxi= cos do paraquat. Essa observação é semelhante àquela feita pela OREGON STATE UNIVERSITY (1979) em cultura de menta, onde também foi aplicada essa mistura.

Os sintomas de fitotoxicidade provocados pelo paraquat nos cultivares de feijäo foram murchamento inicial seguido por rápida necrose, inclusive com morte de folhas inteiras. A fitotoxicidade foi caracterizada por manchas necröticas marrom-claro na folha, não coalescentes. Apenas as folhas que receberam esse herbicida, entretanto, mantiveram esse sintoma. As folhas novas que foram surgindo, não apresentavam sintoma algum de injüria e, com o passar do tempo, a planta foi se recuperando.

O bentazon provocou, no experimento "das àguas", ligeira fitotoxicidade aos cultivares, caracterizado por manchas necróticas marrom-escuro no interior do limbo fo liar. Entretanto, esses sintomas foram observados apenas nas folhas que receberam o herbicida e os novos cres cimentos que foram surgindo não apresentaram sintoma al= gum de injüria. Esses sintomas näo foram observados no experimento "das secas", provavelmente devido ao estresse que a cultura sofreu no início do seu ciclo vegetativo, quando ocorreu uma estiagem reduzindo o efeito tanto do bentazon como do paraquat no feijoeiro. Com isso, os 
Tabela 1. Efeitos das misturas de diferentes doses de bentazon (B) e paraquat (P) (i.a. $\mathrm{kg} / \mathrm{ha})$, no $c v$. Carioca. Os dados representam a porcentagem de injüria nas plantas. Experimento das "secas" de 1981\%.

\begin{tabular}{|c|c|c|c|c|c|c|c|c|}
\hline \multirow{2}{*}{$\begin{array}{l}\text { Dias apōs } \\
\text { apl ícação }\end{array}$} & \multirow{2}{*}{$\dot{B}$} & \multicolumn{7}{|c|}{$P$} \\
\hline & & 0 & & 0,05 & & & 0,10 & \\
\hline & 0 & & 21 & & & 34 & & \\
\hline \multirow[t]{3}{*}{2} & 0,48 & 0 & 6 & $(21)$ & -15 & 11 & $(34)$ & -23 \\
\hline & 0,96 & 0 & 6 & $(21)$ & -15 & 6 & $(34)$ & -28 \\
\hline & 0 & & 16 & & & 29 & & \\
\hline \multirow[t]{3}{*}{4} & 0,48 & 0 & 3 & $(16)$ & -13 & 8 & $(29)$ & -21 \\
\hline & 0,96 & 0 & 4 & $(16)$ & -12 & 3 & (29) & -26 \\
\hline & 0 & & 9 & & & 17 & & \\
\hline \multirow[t]{3}{*}{6} & 0,48 & 0 & 0 & (9) & -9 & 3 & $(17)$ & -14 \\
\hline & 0,96 & 0 & 0 & (9) & -9 & 0 & $(17)$ & -17 \\
\hline & 0 & & 5 & & & 11 & & \\
\hline \multirow[t]{2}{*}{8} & 0,48 & 0 & 0 & (5) & -5 & 0 & $(11)$ & -11 \\
\hline & 0,96 & 0 & 0 & (5) & -5 & 0 & (11) & -11 \\
\hline
\end{tabular}

* Os valores entre parēnteses representam a porcentagem de injüria esperada (E). 
Tabela 2. Efeitos das misturas de diferentes doses de bentazon (B) e paraquat (P) (i.a. kg/ha), no cv. Moruna. Os dados representam a porcentagem de injüria nas plantas. Experimento das "secas" de 1981*.

Dias apōs apl i cação

B

$\mathbf{P}$

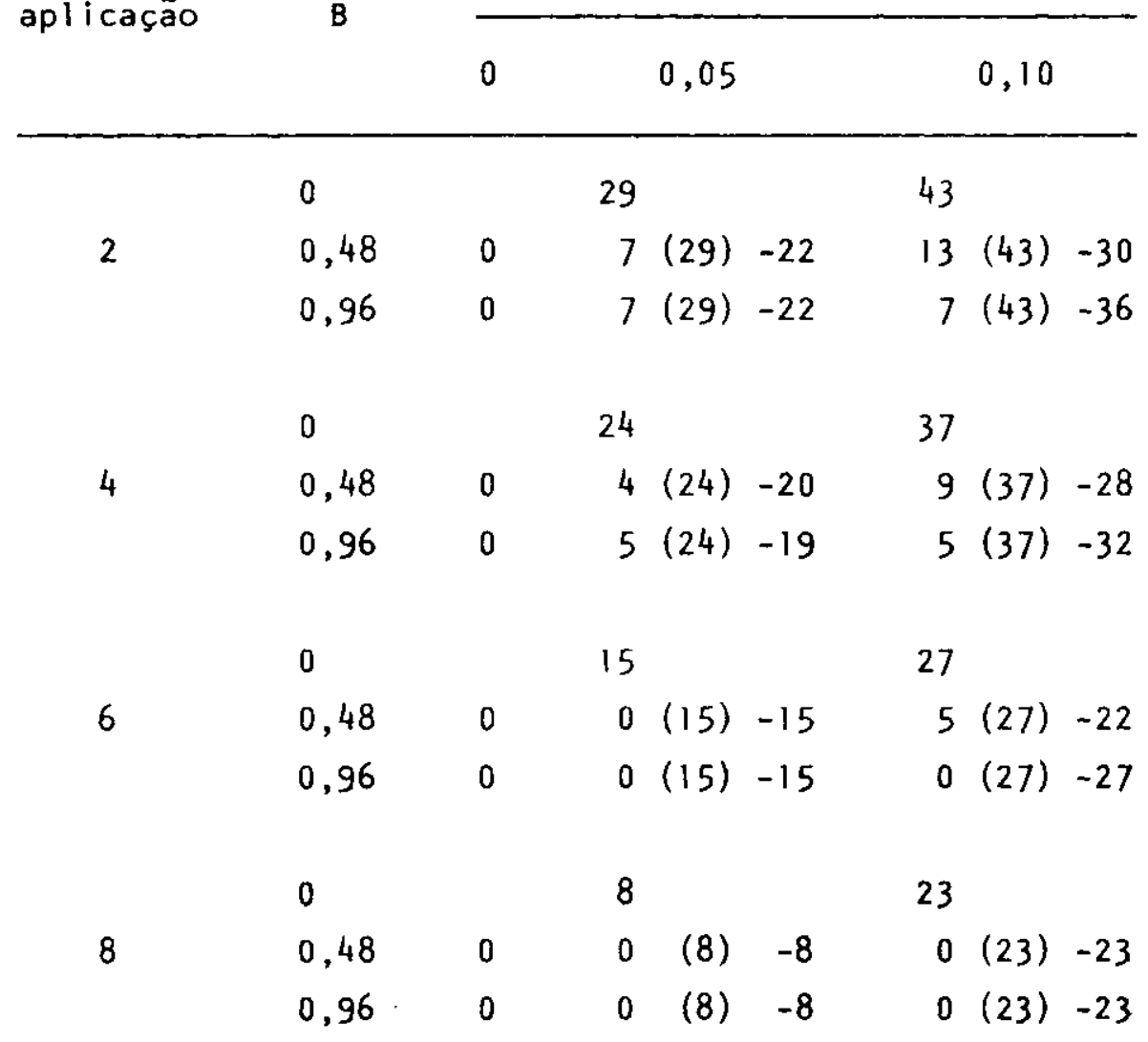

* Os valores entre parênteses representam a porcentagem de injüria esperada (E). 
Tabela 3. Efeitos das misturas de diferentes doses de bentazon ( $B$ ) e paraquat ( $P$ ) (i.a. kg/ha), no cV. Carioca. Os dados representam a porcentagem de injüria nas plantas. Experimento das "ăguas" de 1981*.

Dias após aplicação B

\section{$\mathbf{P}$}

\begin{tabular}{|c|c|c|c|c|c|c|c|c|}
\hline & & 0 & & 0,05 & & & 0,10 & \\
\hline & 0 & & 61 & & & 74 & & \\
\hline \multirow[t]{3}{*}{2} & 0,48 & 7 & 8 & (64) & -56 & 16 & (76) & -60 \\
\hline & 0,96 & 13 & 10 & (66) & -56 & 9 & (77) & -68 \\
\hline & 0 & & 50 & & & 70 & & \\
\hline \multirow[t]{3}{*}{4} & 0,48 & 5 & 6 & (53) & -47 & 13 & $(72)$ & -59 \\
\hline & 0,96 & 10 & 10 & (55) & -45 & 8 & (73) & -65 \\
\hline & 0 & & 45 & & & 65 & & \\
\hline \multirow[t]{3}{*}{6} & 0,48 & 4 & 5 & $(47)$ & -42 & 11 & $(66)$ & -55 \\
\hline & 0,96 & 8 & 8 & (49) & -41 & 5 & (68) & -63 \\
\hline & 0 & & 39 & & & 60 & & \\
\hline \multirow[t]{2}{*}{8} & 0,48 & 3 & 5 & (41) & -36 & 8 & (61) & -53 \\
\hline & 0,96 & 5 & 5 & (42) & -37 & 5 & (62) & -57 \\
\hline
\end{tabular}

* Os valores entre parênteses representam a porcentagem de injüria esperada (E). 
Tabela 4. Efeitos das misturas de diferentes doses de bentazon (B) e paraquat ( $P$ ) (i.a. kg/ha), no $c v$. Moruna. Os dados representam a porcentagem de injüria nas plantas. Experimento das "äguas" de 1981\%.

Dias apōs apl icação

B

p

\begin{tabular}{|c|c|c|c|c|c|c|c|c|}
\hline & & 0 & & 0,05 & & & 0,10 & \\
\hline & 0 & & 63 & & & 74 & & \\
\hline \multirow[t]{3}{*}{2} & 0,48 & 7 & 7 & $(66)$ & -59 & 17 & $(76)$ & -59 \\
\hline & 0,96 & 15 & 10 & $(69)$ & -59 & 9 & $(78)$ & -69 \\
\hline & 0 & & 50 & & & 70 & & \\
\hline \multirow[t]{3}{*}{4} & 0,48 & 5 & 5 & (53) & -48 & 11 & $(72)$ & -61 \\
\hline & 0,96 & 10 & 8 & $(55)$ & -47 & 8 & (73) & -65 \\
\hline & 0 & & 36 & & & 60 & & \\
\hline \multirow[t]{3}{*}{6} & 0,48 & 4 & 3 & $(39)$ & -36 & 9 & $(62)$ & -53 \\
\hline & 0,96 & 8 & 5 & (41) & -36 & 4 & (63) & -59 \\
\hline & 0 & & 29 & & & 55 & & \\
\hline \multirow[t]{2}{*}{8} & 0,48 & 3 & 3 & (31) & -28 & 5 & $(56)$ & -51 \\
\hline & 0,96 & 5 & 3 & (33) & -30 & 3 & $(57)$ & -54 \\
\hline
\end{tabular}

* Os valores entre parênteses representam a porcentagem de injüria esperada (E). 
efeitos antagonisticos das misturas nos cultivares foram mais evidentes no experimento "das äguas" do que no "das secas".

As misturas de bentazon + paraquat provocaram leve clorose foliar, com algumas pontuacooes necróticas. Entre tanto, logo desapareceram e 10 dias apös a aplicação prä ticamente não se notava mais esses efeitos.

0 experimento "das secas" foi prejudicado por longa estiagem e não foi levado até a produção.

No experimento "das äguas", verificou-se que não houve diferenças significativas entre os tratamentos den tro dos cultivares Carioca e Moruna (Tabela 5). Entretañ to, quando se comparou as produçōes dos cultivares $\mathrm{Ca}-$ rioca e Moruna dentro de cada tratamento desse experimen to observou-se que no tratamento paraquat $0,10 \mathrm{~kg} / \mathrm{ha}, \bar{a}$ produção do cv. Moruna $(1133,5 \mathrm{~kg} / \mathrm{ha})$ foi significativamente maior do que a produção do cv. Carioca $(758,25 \mathrm{~kg} /$ /ha) ao nivel de $1 \%$ de probabilidade pelo teste $\mathrm{F}(14,38 \% *)$. No tratamento de bentazon + paraquat a $0,48+0,05 \mathrm{~kg} / \mathrm{ha}$, respectivamente, tambēm a produção do cv. Moruna ( $1094,50 \mathrm{~kg} / \mathrm{ha})$ foi significativamente maior do que a produção do $\mathrm{cv}$. Carioca $(842,50 \mathrm{~kg} / \mathrm{ha})$, ao $\mathrm{ni}$ vel de $5 \%$ de probabilidade pelo teste $F(6,48 \%)$. Nos demais tratamentos, não houve diferenças significativas en tre as produções desses cultivares.

Em relação às plantas daninhas, os efeitos das mis turas de bentazon + paraquat variaram conforme a especie, dose de cada componente presente na mistura e as condições em que o experimento foi realizado.

Em se tratando de gramíneas, verificou-se que, no experimento "das äguas", onde ocorreu boa precipitação, a) ta temperatura e solo argiloso, os efeitos foram nitidamente sinergísticos. Esse fenômeno pôde ser observado para o capim-marmelada (Tabela 6) e capim-pé-de-gailinha (Tabela 7). Entretanto, no experimento "das secas", com 


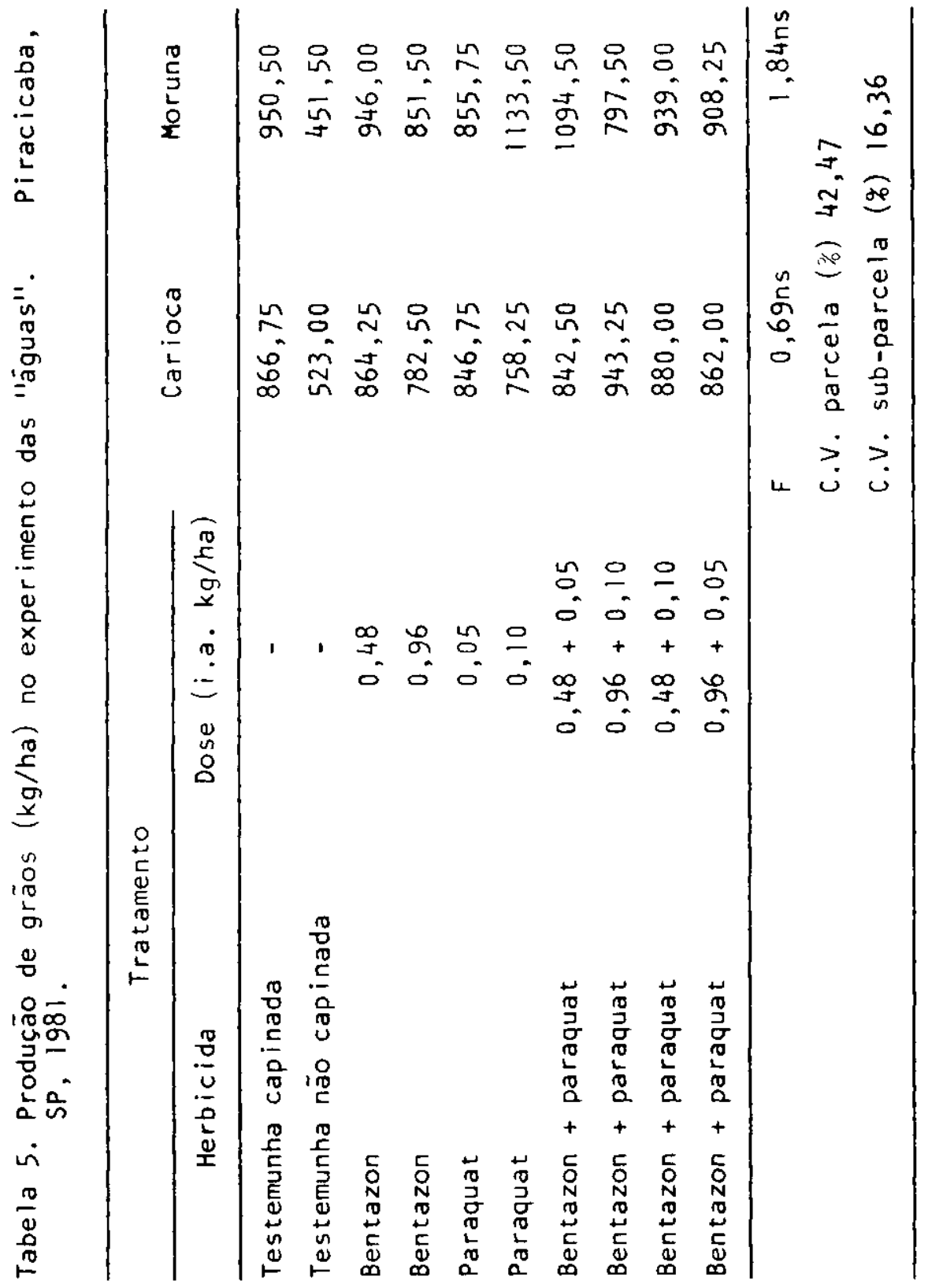


Tabela 6. Efeitos das misturas de diferentes doses de bentazon (B) e paraquat ( $P$ ) (i.a. $\mathrm{kg} / \mathrm{ha}$ ), no capim-marmelada (Brachiaria plantaginea (Link.) Hitch). Os dados representam a porcentagem de injüria nas plantas. Experimento das "águas" de $1981:$.

Dias apōs aplicação

8

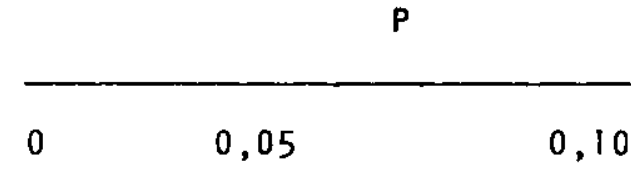

0

2

$0,48 \quad 0$

0,96

5

0

4

0,48

0

0,96

0

55

$80 \quad(55)+25$

$75(55)+20$

47

$73(47)+26$

$67(47)+20$

0,96

0

0

8

$\begin{array}{ll}0,48 & 0 \\ 0,96 & 0\end{array}$

40

$70(40)+30$

$70(40)+30$
95

93 (95) -2

$93(95)-2$

83

$95(83)+12$

$95(83)+12$

74

$90(74)+16$

$93(74)+19$

65

$80(65)+15$

$85(65)+20$

* Os valores entre parênteses representam a porcentagem de injüria esperada (E). 
Tabela 7. Efeitos das misturas de diferentes doses de bentazon (B) e paraquat (P) (i.a. kg/ha), no capim-pé-de-gal inha (Eleusine indica Gaertn.). Os dados representam a porcentagem de injüria nas plantas. Experimento das "äguas" de $1981 *$.

Dias apōs apl icação

B

$p$

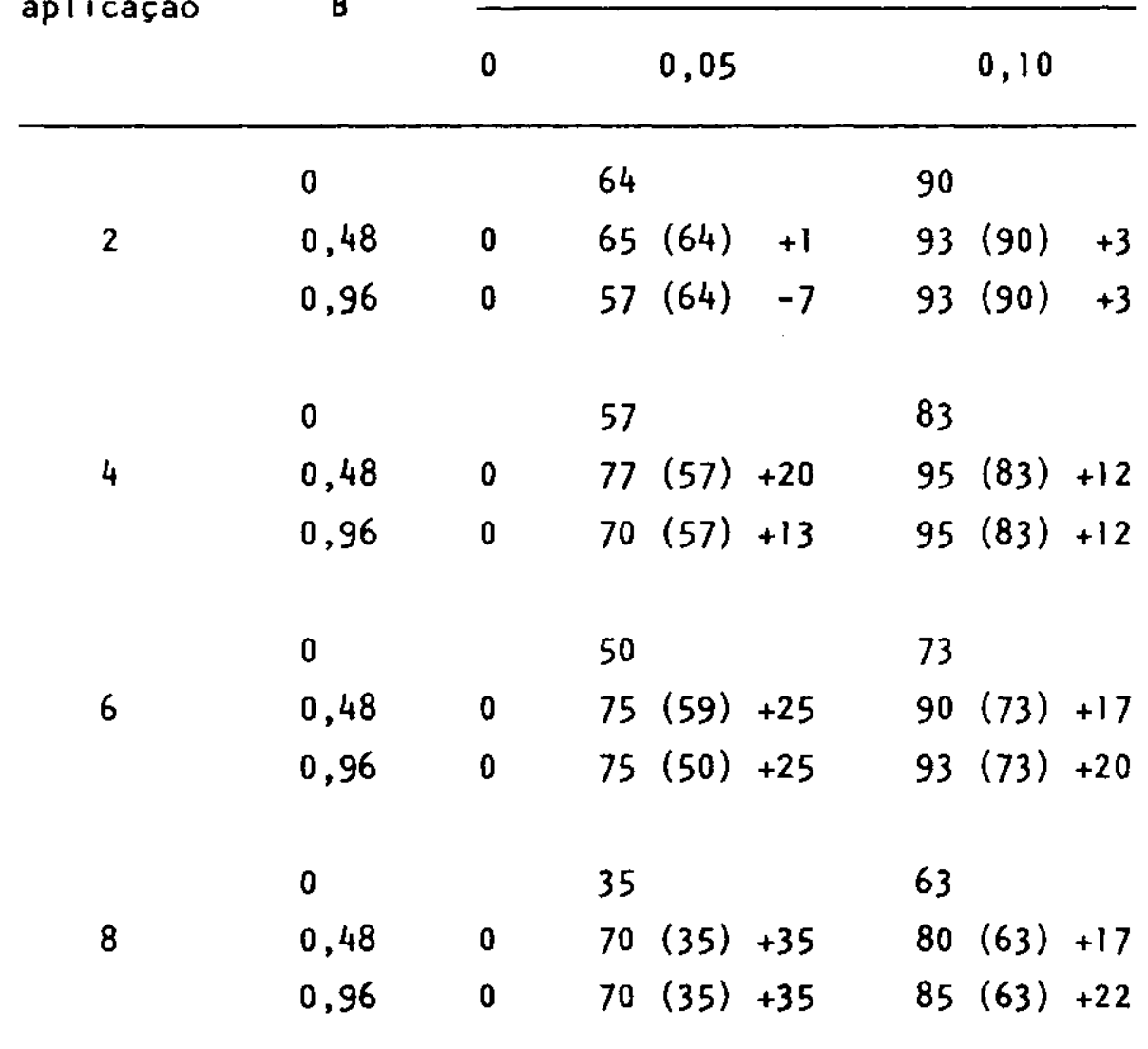

* Os valores entre parênteses representam a porcentagem de injüria esperada (E). 
baixa precipitação, menor temperatura e solo arenoso, ocorreu nitido efeito antagonístico no capim-colchão, pa recendo que o bentazon "protegeu" essa espécie dos efeitos fitotóxicos do paraquat (Tabela 8).

Na beldroega, que ocorreu no experimento "das secas" os efeitos foram sinergísticos, principalmente com a mistura de doses menores, jā a partir do 20 dia apōs a aplicação (Tabela 9). Fato semelhante ocorreu em relação à guanxuma, tambëm no experimento "das secas", onde os efeitos sinergísticos das misturas foram se acentuando com o passar do tempo, sendo mais evidentes ao 89 dia após a aplicação, principalmente com a mistura de doses menores (Tabela 10).

No apaga-fogo, no experimento "das äguas", ocorreu nitido efeito sinergístico ao 89 dia apōs a aplicação, provocado pelas misturas onde o paraquat entrou com a do se menor. A injüria provocada nessa espēcie pelas mistū ras, foi quase total (Tabela ll). Entretanto, no carrapicho-de-carneiro, também no experimento "das águas", os efeitos foram apenas aditivos, pois todos os tratamentos provocaram altas porcentagens de injüria nessa espécie (Tabela 12).

SUMMARY

EFFECTS OF BENTAZON AND PARAQUAT MIXTURES ON WEEDS AND ON DRY BEANS (Phaseolus vulgaris L.)

The present research was conducted at Escola Superior de Agricultura "Luiz de Queiroz", Piracicaba, SP, in 1981, with the objective to study behaviour of the herbi cides bentazon and paraquat applied separately or in mix tures in some bean cultivars and in some weeds. Two experiments were conducted in the field. The bean culti- 
Tabela 8. Efeltos das misturas de diferentes doses de bentazon (B) e paraquat (P) (i.a. $\mathrm{kg} / \mathrm{ha}$ ), no capim-colchão (Digitaria sanguinalis (L.) Scop.). Os dados representam a porcentagem de injürla nas plantas. Experimento das "secas" de $1981 \%$.

Dias após aplicação B

$\mathbf{P}$
0
0,05
0,10

\begin{tabular}{|c|c|c|c|c|c|c|c|}
\hline & 0 & & 56 & & 70 & & \\
\hline \multirow[t]{3}{*}{2} & 0,48 & 0 & $25(56)$ & -31 & 63 & $(70)$ & -5 \\
\hline & 0,96 & 0 & $34(56)$ & -22 & 45 & $(70)$ & -25 \\
\hline & 0 & & 36 & & 69 & & \\
\hline \multirow[t]{3}{*}{4} & 0,48 & 0 & $20(36)$ & -16 & 63 & (69) & -6 \\
\hline & 0,96 & 0 & $24(36)$ & -12 & 35 & (69) & -34 \\
\hline & 0 & & 26 & & 60 & & \\
\hline \multirow[t]{3}{*}{6} & 0,48 & 0 & $14(26)$ & -12 & 44 & $(69)$ & -16 \\
\hline & 0,96 & 0 & $15(26)$ & -11 & 29 & $(60)$ & -31 \\
\hline & 0 & & 16 & & 49 & & \\
\hline \multirow[t]{2}{*}{8} & 0,48 & 0 & $6(16)$ & -10 & 33 & (49) & -16 \\
\hline & 0,96 & 0 & $9(16)$ & -7 & 17 & (49) & -32 \\
\hline
\end{tabular}

* Os valores entre parênteses representam a porcentagem de injüria esperada (E). 
Tabela 9. Efeitos das misturas de diferentes doses de bentazon ( $B$ ) e paraquat (P) (i.a. kg/ha), na beldroega (Portulacea oleracea L.). Os dados re presentam a porcentagem de injüria nas plantas. Experimento das "secas" de 1981*.

Dias apös apl icação

B

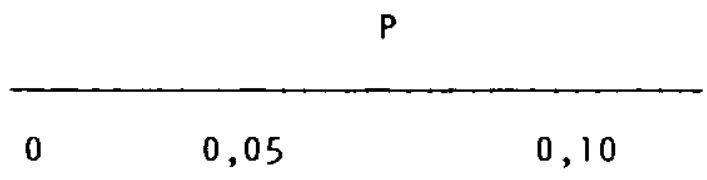

0

2

0,48

0,96

0

4

$$
0,48
$$

0,96

0

6

$$
\begin{aligned}
& 0,48 \\
& 0,96
\end{aligned}
$$

0

8

$$
\begin{aligned}
& 0,48 \\
& 0,96
\end{aligned}
$$

46

43

33

8

7

60

47

50

37

65
66

76

$3384(73)+11$

$87(84)+3$

75 (79) -4

$89(87)+2$

65

$89(69)+20$

$89(78)+11$

$87(83)+4$

$93(88)+5$

$\therefore$ Os valures entre parênteses representall a porcentagem de injüria esperada (E). 
Tabela 10. Efeitos das misturas de diferentes doses de bentazon (B) e paraquat ( $P$ ) (i.a. $\mathrm{kg} / \mathrm{ha})$, na guanxuma (Sida glaziovii K. Sch.). Os dados representam a porcentagem de injüria nas plan tas. Experimento das "secas" de 1981\%.

Días apōs aplicação

B

\section{$\mathbf{P}$}

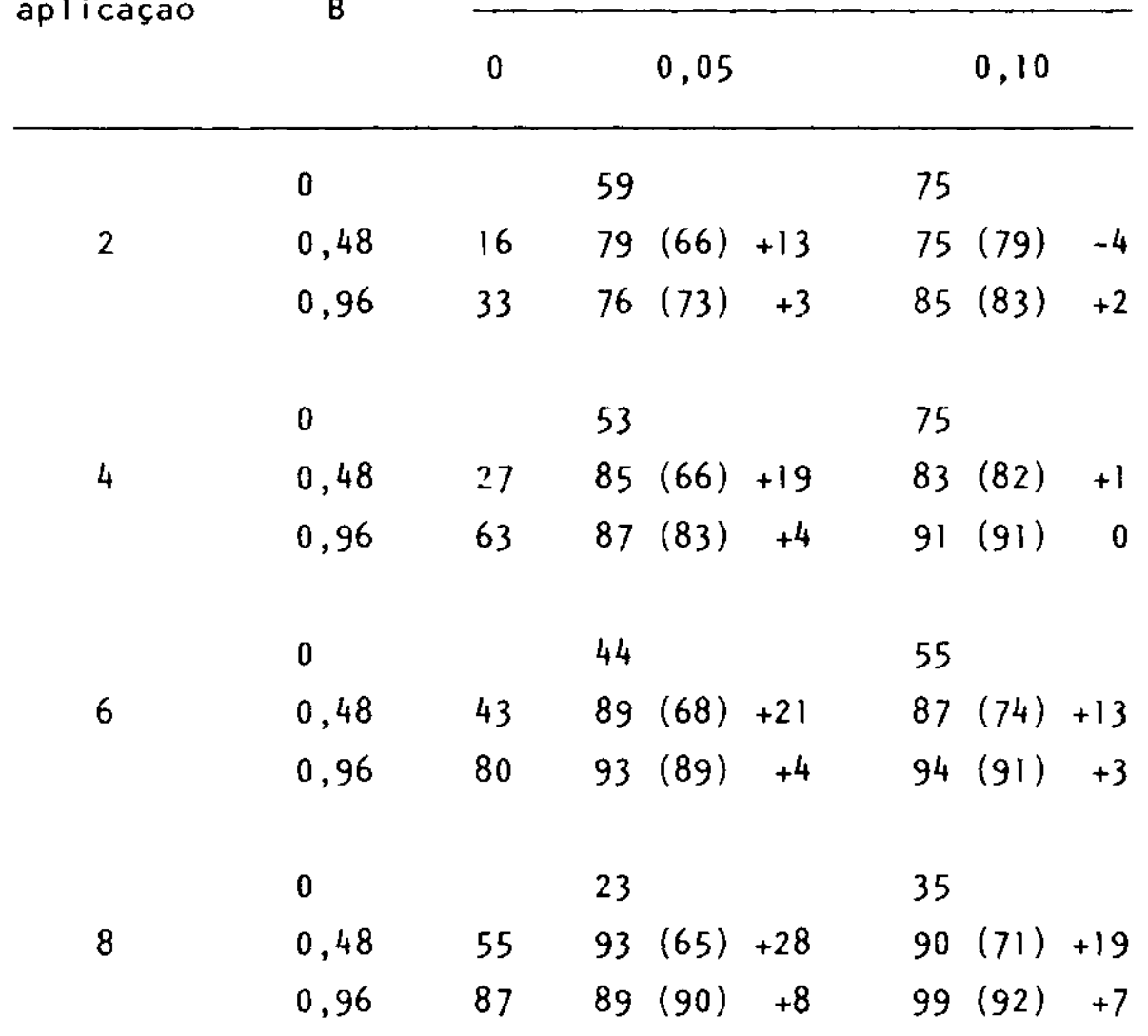

$\therefore$ Os valores entre parénteses representam a porcentagem de injüria esperada (E). 
Tabela 11. Efeitas das misturas de diferentes doses de bentazon (B) e paraquat (P) (i.a. kg/ha), no apaga-fogo (Alternanthera ficoidea (L.) $\mathrm{R}$. $B r$.$) . Os dados representam a porcentagem de$ injürila nas plantas. Experimento das "äguas" de $1981 *$.

Dias após aplicaçāo

B

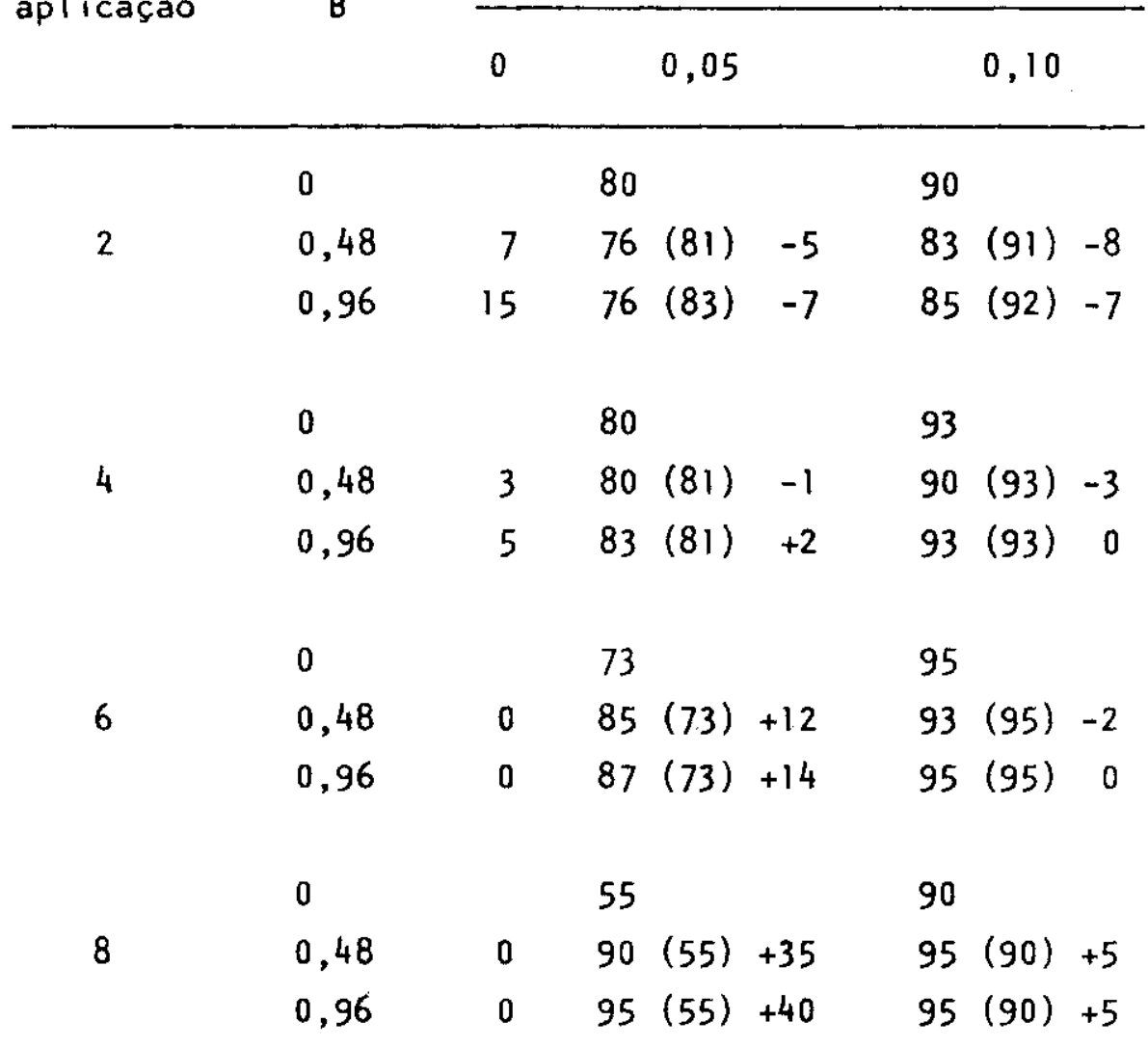

* Os valores entre parênteses representam a porcentagem de injüria esperada (E). 
Tabela 12. Efeitos das misturas de diferentes doses de bentazon (B) e paraquat ( $P$ ) (i.a. kg/ha), no carrapicho-de-carneiro (Acanthospermun hispidum D.C.). Os dados representam a porcentagem de injúria nas plantas. Experimento das "äguas" de 1981:.

Dias apōs apli cação
B

$\begin{array}{lll}0 & 0,05 & 0,10\end{array}$

0

2

$$
0,48
$$

0,96

91

87

0

4

0,48

0,96

95

$95 \quad 100$

76

6

0

0,48

0,96

0

8

$0,48 \quad 100$

90

94

87

55

100
97

100

(99) +1

(99) +1

94

98

99

(99) -2

(99) -5

(99) 0

90

$100(100) 0$

$100(100) 0$

80

$100(100) \quad 0 \quad 100(100) \quad 0$

$100(100) \quad 0 \quad 100(100) \quad 0$

70

10

\section{5}

$(100) 0$

$(100) \quad 0$

$100(100) 0$

$100(100) 0$

* Os valores entre parênteses representam a porcentagem de injüria esperada (E). 
vars studied were Carioca and Moruna. The treatments carried on were: bentazon at 0,48 and $0,96 \mathrm{~kg} / \mathrm{ha}$; paraquat at 0,05 and $0,10 \mathrm{~kg} / \mathrm{ha}$ and the tank mixtures with $0,48+0,05 ; 0,96+0,10 ; 0,48+0,10$ and $0,96+0,05 \mathrm{~kg} /$ /ha of bentazon + paraquat respectively. Visual evaluations were performed to quantify the percentage of injury on the bean cultivars, and on the weeds. Colby formu la was utilized to evaluate the effects of the mixtures. The results showed that the mixtures induced evident antagonistic effects on the studied cultivars. The treatments carried in the field had no influence on the Cario ca and Moruna cultivars yield. On sandy soil and with low precipitation, the synergism of the mixtures was evi dent on Sida glaziovii K. Sch. and Portulacca oleraceá L. In clay soils with normal precipitations, the synergistics effects were evident on Brachiaria plantaginea (Link) Hitch., Eleusine indica (L.) Gaertn., and Alternanthera ficoidea (L.) R. Br.

\section{LITERATURA CITADA}

AKOBUNDU, I.0.; SWEET, R.D.; DUKE, W.B., 1975. A method of evaluating herbicide combinations and determining herbicide synergism. Heed Science. Champaign 23(1): 20-25.

COLBY, S.R., 1967. Calculating synergistic and antagonistic responses of herbicide combinations. Weeds. Ur bana 15(1): 20-22.

FRANC0, L.A.; CATTANEO, S.L.F., 1974. Comportamento de paraquat em misturas com diuron ou ametryne no con trole pós emergente de ervas daninhas (nota prévia). In: Resumos do X Seminäio Brasileiro de Herbicidas e Ervas Daninhas, Santa Maria, p. 35-36. 
GOWING, D.P., 1960. Comments on tests of herbicide mixtures. Weeds. Urbana 8(3): 379-391.

HAMILL, A.S.; SMITH, L.W.; SWITZER, C.M., 1972. Influen ce of phenoxy herbicides on picloram uptake and phytotoxicity. Weed Science. Urbana 20(3): 226-229.

HATZIOS, K.K., 1981. Synergistic interactions of tebuthiuron with EPTC $+R-25788$ and butylate $+R-25788$ in corn (Zea mays). Weed Science. Champaign 29(5): $601-604$.

HICKS, R.D.; ADDISON, D.A.; EDMONOSON, J.B.; KEATON, J. A.; MCNEILL, K.E.; WEBSTER, H.L., 1976. Oryzalin: weed control in no-till soybeans. In: Proceedings of the 29th Annual Meeting Southern Weed Science Society. Dallas, p. 125-132.

KAPUSTA, G.; STRIEKER, C.F.; MCGINNITY, P.J., 1978. IVYleaf morningglory control in soybeans. In: Proceedings North Central Weed Control Conference. Carbonale, v. 33, p. 66. Apud: Weed Abstracts. 0xford 29 (8): 264-265, 1980 (ref. 2373).

MORAES, M.V.; FORSTER, R.; STRIPECKE, W., 1966. Testes preliminares com novos herbicidas e suas combinações em aplicação em pré e post-emergência às invasoras na cultura do café. In: VI Seminärio Brasileiro de Herbicidas e Ervas Daninhas. Sete Lagoas, p. 177-183.

OREGON STATE UNIVERSITY, 1979. Paraquat-bentazon interac tion in peppermint. In: OREGON STATE UNIVERSITY. Weed Control Research Report: Peppermint. Corvallis, p. B-29-B-30.

PAROCHETTI, J.V., 1979. Combination of three residual herbicides for fall panicum control inno-tillage corn. In: Proceedings of the $33^{\text {rd }}$ Annual Meeting of the North-eastern Weed Science Society. Boston, p. 4. 
PAULO, E.M.; TOLEDO, N.P.; FORSTER, R., 1980. Controle de mono e dicotiledôneas na cultura de soja em pós-emergência, pela combinação de mefluidide e bentazon. In: Resumos do X 111 Congresso Brasileiro de Her bicidas e Ervas Daninhas. Ilhéus/Itabuna, p. 57.

PRENDEVILLE, G.N.; JAMES, C.S.; WARREN, G.F.; SCHREIBER, M.M., 1969. Antagonistic responses with combinations of carbamate and growth regulator herbicides. Weed Science. Urbana 17(3): 307-309.

RAMOS, M., 1976. Efeito de derivados do àcido propiônico no controle do papuã (Brachiaria plantaginea) em tratamento de pös-emergência na cultura da soja. Mis tura e associação ao bentazon. In: Resumos do XI Seminärio Brasileiro de Herbicidas e Ervas Daninhas. Londrina, p. 79.

RETZINGER Jr., E.J.; ROGERS, R.L.; CRAWFORD, S.H., 1981. Weed control in soybeans with BAS-9052, bentazon and acifluorfen. In. Proceedings of the 34 th Annual Meeting Southern Weed Science Society. Dallas, p. 56.

SCHWEIZER, E.E., 1979. Weed control in sugarbeets (Beta vulgaris) with mixtures of cycloate and ethofumesate. Weed Science. Champaing 27(5): 516-519.

SIMONDS, B.L.; BANKS, P.A., 1981. Use of preemergence herbicides in reduce tillage soybeans. In: Proceedings of the 34 th Annual Meeting Southern Weed Science Society. Dallas, p. 80-84.

TRIPLETT Jr., G.B.; LYTLE, G.D., 1972. Control and ecology of weeds in continuous corn grown without tillage. Weed Science. Urbana 20(5): 453-457. 